\title{
Thermal Factor of Aluminium High pressure Die Casting Container (Mould) to achieve Six Sigma Quality of Castings
}

\author{
Suraj Marathe ${ }^{1}$ \\ ${ }^{1}$ Research Scholar, Mechanical Engineering Department, \\ Assam Don Bosco University, \\ Guwahati, India
}

\author{
Dr. Carmo Quadros ${ }^{2}$ \\ ${ }^{2}$ Ph.D Supervisor, \\ Assam Don Bosco University, \\ Guwahati, India
}

\begin{abstract}
This paper deals with the analysis of the temperature factors of aluminium high pressure die casting Container (mould). It also describes the development of expression for preheating temperature factor of mould to maintain the molten aluminium temperature, which gives the six sigma quality product depending on the degree of preheating of mould. The monitored temperature factors are very much important in the die-casting process, which is positively reflected in production efficiency and the quality of the casting. In die casting, the melted metal is pressed under high temperature into a mould cavity of significantly lower temperature. The mould is then exposed to a thermal strain of individual surface layers of the mould material. The speed of cooling of the castings in the metal mould increases, causing an increase of thermal gradients in the casting. Intensive heat exchange between the castings And the metal mould harms fluidity, which increases the danger of incomplete replenishment and the occurrence of cold joints. Analysis and optimization were performed with the help of ProCast Simulation software which uses Finite Element Analysis Technology.
\end{abstract}

Keywords - High Pressure Die-casting (HPDC; Preheating temperature; Six Sigma quality of a casting; ProCast

\section{INTRODUCTION}

Die casting is amongst the highest volume, massproduced items manufactured by the metalwork industry, and they can be found in thousands of consumer, commercial and industrial products. Aluminium Alloy is the light in weight while processing high dimensional Stability for complex shapes and thin walls. Even in a completely controlled Process defect in casting are observed and hence casting process is also known as a process of uncertainty that challenges explanation about the cause of casting defect.

To identify the casting defect and problem-related to casting the study is aimed at research work. In today's world, a casting production without any defect is almost impossible so all the process parameters that contribute to casting rejection were studied. Critical parameters like thermal (temperature of Molten metal, Mould, filling chamber) and pressure (Intensified, clamping) were taken for the analysis. This temperature depends on the temperature of the material, the quantity of the metal, the method of the cooling of the casting mould, the thermal conductivity of the mould material and the time during which the casting remains in the mould. The current rejection level in casting is around $11-13 \%$ so the attempts are being made to bring and keep the rejections in the die casting process as per the Six Sigma limit [1]. Various defects such as porosity, blowhole, improper filling time, hot spots, and misruns in the castings were properly studied $[2,3]$. Analysis and optimization of the preheating temperature of mould were performed with the help of ProCast Simulation software.

Die cast parts are important components of products ranging from toys to automobiles. Parts can be as simple as a sink faucet or as complex as a connector housing. Die casting is one of the fastest and most cost-effective methods for producing a wide range of components [4], where molten metal is injected into a permanent mould at high speed $(10-100 \mathrm{~m} / \mathrm{sec})$ and under high pressure. However, to achieve maximum benefits from this process, it is important to maintain the critical parameters of the process $[1,5]$. Despite recent scientific research engaged in the issue of die casting, many factors and problems related to this technology remain unexplained. It also refers to the study of the impact of thermal factors of casting on the quality of the castings.

\section{LITERATURE REVIEW}

The global market is becoming more and more quality conscious. To compete in such an environment, companies need to adopt an efficient technique that can assess and take a diagnostic approach to meet customer needs and expectations. Nowadays, the industrial world has realized that the Six Sigma philosophy is certainly a viable solution to their shop floor problems [1].

The quality of casting is influenced by many Thermal and technological factors, the basics of which are Temperature of cast alloy, the temperature of the filling chamber, and the temperature of the mould. This temperature depends on the temperature of the material, the quantity of the metal, the method of the cooling of the casting mould, the thermal conductivity of the mould material, and the time during which the casting remains in the mould $[3,6]$; Die casting of metals are the highest technological level of metals and their alloys casting into metal molds. The quality of pressure die castings are affected by numerous technological factors, such as pressing velocity during a casting cycle, increase pressure and time of filling a mold cavity [7] 
A stable finite difference scheme, the component-wise splitting method, a 3D thermal analysis system has been introduced and adopted in the mathematical modeling of the heat transfer problem in the die-casting process. [8]

To improve the mechanical properties of aluminum-alloy parts, the semi-solid die casting process is used in the manufacture of automobile components. Semi-solid die casting has a different die structure from those of general die casting and squeeze casting. Because the oxide skin is produced during the reheating process will

cause defects when it fills the die cavity, in semi-solid diecasting the most important factors are the filling velocity, the area of the gate, and the position, size, the number of overflows. [9]

Product manufactured from every manufacturing process shows some defects. For supplying a quality product to the customer these defects must be reduced. There can be defects in a die-casted product like porosity, blowhole, non-filling, etc. If they are within the control limit then the product is acceptable otherwise rejected [3]. Every manufacturer tries to manufacture defect-free components but practically it is not possible and some defects remain in the component and lead to rejection of the component. This rejection can be minimized upon a certain extent. Different methods can be used to minimize defects, some of them are; by improving process parameters, by design modifications, or both. [10 11]

Determining the optimal process parameter setting will significantly improve the mould yield, output ratio of metal, shorten manufacturing period, save energy and resource, During the injection of molten metal the flow inside the shot sleeve before plunger should be laminar if these speeds, the injection pressure is not set properly the flow of metal will be disturbed and convert into turbulence and there will be a possibility of formation of porosity during the process. Pouring temperature generally varies from 650 to 800 degrees Celsius. Generally, a better fluidity in higher temperature is connected with the Preheating is done to remove the possibility of formation of temperature gradients. If we increase the preheat temperature from a particular range then it may affect the die coating and also it may create defects like rough surface finish and also if the temperature is removed considerably then this may cause a particularly chilling effect which in turn leads to less solidification of core and due to this difference in solidification rate defects like solidification shrinkage may occur decreasing viscosity. [12]

With changing times and increased competition, it has become mandatory to reduce the rejection level in the die casting process. After studying the literature review it was found that a lot of work has been done on the hydraulic die casting process one way or another. Literature reveals that a lot of work has been done optimization of the die casting process, [13 14] redesign the gating and runner system to increase the overall efficiency [5]. Optimize process parameters using DOE and Taguchi methodology [1, 11], flow simulation of the die casting process, modeling and simulation of alloy steel casting, [15 16] Thermal factors affecting the die casting process [17], etc.

Based on the literature survey and the subsequent analysis of gaps the present work aims to investigate the effects of thermal factors in a die casting process on the quality of cast product and optimize the process using ProCast Simulation.

\section{PROCESS PARAMETERS}

The Hydraulic die casting process is governed by its process parameters so it is required to study its process parameters and its effects. Mostly casting defects are concerned with process parameters. Hence one has to control the process parameter to achieve zero-defect parts. The metal flow in the die castings is influenced by the pouring temperature, die temperature, and the thermal conductivity of alloy. In a typical die casting machine, the molten metal is poured in the shot sleeve through a ladle after the die is closed. A movement of plunger (piston) forces the metal through the die resulting in that the moveable part coincides with the fixed part.

\section{A. Various Process Parameters}

In a practical die casting process is quite tough to judge the exact cause for a particular Defect because they are quite intuitive, so first of all, it is required to identify process parameters that can affect the process considerably and can change the output with reasonable weight. A cause and effect diagram is drawn for casting defects as shown in fig. 1 A Pressure die casting essentially consists of following parameters such as:-

- Pouring Molten temperature

- Preheat temperature

- Filling time

- Riser design

- Plunger Velocity

- Die holding time

- Injection Pressure

- Die coat material

- Solidification Time

- Die coat thickness

- Cooling System 


\section{Cause and Effect Diagram for Casting Defects}

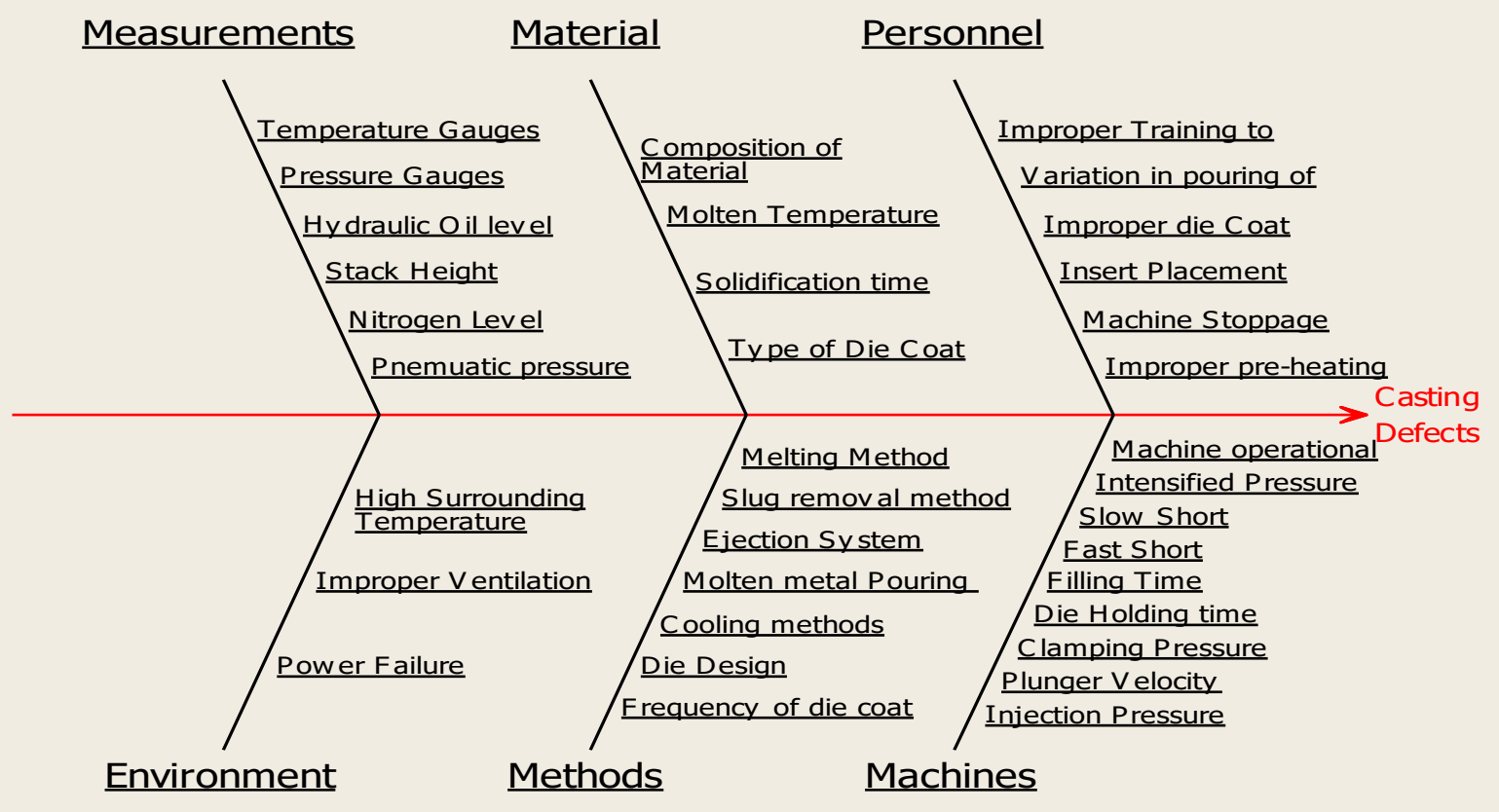

Fig 1: Cause and Effect Diagram for Casting Defects

The process parameters which are critical and can affect the process considerably for producing defective castings are:-

Pouring temperature: - Pouring temperature generally varies from 650 to 800 degrees Celsius. When we pour aluminium alloy then its fluidity is completely dependent upon pouring temperature. Generally, a better fluidity in higher temperature is connected with the decreasing viscosity and surface tension of molten metal with the increasing of pouring temperature, which leads to the increasing filling speed. At the same time, the heat capacity of molten alloy rises with increasing temperature of the pouring, what increases by filling time?

The pouring temperature also affects the microstructure formation to a greater extent and which in turn affects the final structure and toughness of casting products

Preheat temperature: - Preheating in the gravity die casting is done to remove the possibility of the formation of temperature gradients. If we increase the preheat temperature from a particular range then it may affect the die coating and also it may create defects like rough surface finish and also if the temperature is removed considerably then this may cause a particularly chilling effect which in turn leads to less solidification of core and due to this difference in solidification rate defects like solidification shrinkage may occur. A significant precondition for the production of high-quality castings by keeping an optimum temperature of the respective parts of the mould cavity surfaces.

Injection pressure: - This is the pressure that causes the material to flow, and it may be approximately measured by a transducer located in the hydraulic line or the nozzle. There is a direct relationship between injection pressure and injection line pressure. This is the primary pressure for injecting $95 \%$ of the molten metal into the closed mould. Normally, the highest pressure and fastest fill rate are the best conditions.

Clamp pressure: - The only reason to have clamp pressure is to keep the mould closed against injection pressure. Therefore, the amount of clamp pressure required is based on the material being moulded. The easier flow materials require less injection pressure, thus they require less clamp pressure. Conversely, the stiffer flow materials will require more injection pressure, thus more clamp pressure.

Holding pressure: - Once the majority of the molten metal (95\%) has been injected using standard injection pressure [18], the machine should drop into hold pressure. This pressure is about half of the injection pressure and is used to finish filling the mould by packing the molecules together in an orderly fashion. Hold pressure is required until the gate freezes off, normally in 3 to 4 seconds. Once that happens, hold pressure has no more effect on the molecules on the other side of the gate.

The temperature of mould: - the casting quality is significantly affected by the temperature regime of the mould. When the mould is cold, joints are formed in the casting and the surface quality of casting is insufficient. When the mould is very hot, the alloys are bonded to the mould and the amount of bubbles and pores grows. The temperature of the mould will be maintained constantly at 
approximately $1 / 3$ of the temperature of the cast metal. This is achieved by thermoregulation of the mould.

The temperature of a filling chamber: - when the chamber is preheated before the casting process, the temperature of the cast alloy does not decrease before filling of the mould cavity [19]. The increased rate of cooling of castings in a metal mould in comparison with a sand mould causes an increase in temperature gradients in the casting.

\section{DEVELOPMENT OF PREHEATING TEMPERATURE EQUATION FOR HPDC}

A significant precondition for the production of highquality castings is keeping an optimal temperature of the respective parts of the mould cavity surface. This temperature depends on the temperature of the material. The quantity of the metal, the method of the cooling of the casting mould, the thermal conductivity of the mould material and the time during which the casting remains in the mould.

The following applies for the thermal balance per one cycle:

Where:

$$
Q_{1}+Q_{2}-Q_{3}-Q_{4}=Q_{1}
$$

$\mathrm{Q}_{1}=$ Is the amount of heat required for preheating of the mould [ J]

$\mathrm{Q}_{2}=$ Is the amount of heat injected by Casting [ $\mathrm{J}$ ]

$\mathrm{Q}_{3}=$ Is the amount of thermal energy

transferred from the casting to the mould [ J ]

$\mathrm{Q}_{4}=$ Is the amount of heat minus the heat

of the mould leaving the casting [ J ]

Equation (1) becomes,

$$
Q_{2}-Q_{3}-Q_{4}=0
$$

Then the amount of heat injected by the casting $\left(\mathrm{Q}_{2}\right)$ :

$\mathrm{Q}_{2}=w\left[C_{\mathrm{pl}}\left(T_{\ell}-T_{s}\right)+\ell+C_{\mathrm{ps}}\left(T_{s}-423.3\right)\right] \ldots$

Where:

$\mathrm{w}=$ Is the weight of casting +0.6 of intake weight $[\mathrm{Kg}]$

$\mathrm{C}_{\mathrm{pl}}=$ Is the Specific heat of molten Aluminum $\left[\frac{\mathrm{J}}{\mathrm{KgK}}\right]$

$\mathrm{T}_{\ell}=$ Is the Temperature of the liquid Aluminum $\left[{ }^{\circ} \mathrm{C}\right]$

$\mathrm{T}_{\mathrm{s}}=$ Is the Solidus Temperature $\left[{ }^{\circ} \mathrm{C}\right]$

$\ell=$ Is the latent heat of Solid Aluminum $\left[\frac{\mathrm{J}}{\mathrm{Kg}}\right]$

$\mathrm{C}_{\mathrm{ps}}=$ Is the Specific heat of Solid Aluminum $\left[\frac{\mathrm{J}}{\mathrm{KgK}}\right]$

The amount of heat transmitted by the casting to the mould $\left(Q_{3}\right)$

$\mathrm{Q}_{3}=\alpha \mathrm{A}\left(\mathrm{T}_{\ell}-\mathrm{T}_{\mathrm{m}}\right) \mathrm{t}$

Where:

$\alpha=$ Is the heat transfer coefficients $\left[\mathrm{Wm}^{-2} \mathrm{k}^{-1}\right.$ ]

$\mathrm{A}=$ Is the casting Surface $\left[\mathrm{m}^{2}\right]$

$\mathrm{T}_{\mathrm{m}}=$ Is the Temperature of the mould $\left[{ }^{\circ} \mathrm{C}\right]$ $\mathrm{t}=$ Is the cooling time $(\mathrm{s})$

The Amount of heat leaving the mould with the casting $\left(\mathrm{Q}_{4}\right)$

$$
\mathrm{Q}_{4}=\mathrm{wC}_{\mathrm{ps}}\left(\mathrm{T}_{2}-20\right)
$$

Where:

$\mathrm{T}_{2}=$ Is the temperature of the casting taken out from the mould $\left[{ }^{\circ} \mathrm{C}\right]$

The heat balance equation (2) as follows:

$$
\mathrm{Q}_{2}=\mathrm{Q}_{4}+\mathrm{Q}_{3}
$$

Substituting (3), (4) and (5) in equation (2), we get

$$
\begin{aligned}
& \mathrm{w}\left[\mathrm{C}_{\mathrm{pl}}\left(\mathrm{T}_{\ell}-\mathrm{T}_{\mathrm{s}}\right)+\ell+\mathrm{C}_{\mathrm{ps}}\left(\mathrm{T}_{\mathrm{s}}-423.3\right)\right]=\alpha \mathrm{A}\left(\mathrm{T}_{\ell}-\right. \\
& \left.\mathrm{T}_{\mathrm{m}}\right) \mathrm{t}+\mathrm{wC}_{\mathrm{ps}}\left(\mathrm{T}_{2}-20\right)
\end{aligned}
$$

Equation (7) will be used to find out the preheating temperature required for the mould (container) which depends on the weight and surface area of the casting, Specific heat of the molten and Solid aluminium, Temperature of the molten and solidus aluminium, latent heat of solidus aluminium, heat transfer coefficient and temperature of casting when taken out from the mould.

\section{EXPERIMENTAL VALIDATION:}

The above heat balance Equation validation was carried out by Simulation using Procast Software. The experimental setup consists of High pressure die casting machine of $100 \mathrm{~T}$, a diesel-fired holding furnace, and a Close loop cooling system. The die-casted rotor 100S, M50 and B48 (which is used for the motors) product selected for validation, which varies its diameter from $50 \mathrm{~mm}$ to $250 \mathrm{~mm}$ and length varies from $25 \mathrm{~mm}$ to $300 \mathrm{~mm}$

A. Validation for the die casting of $100 \mathrm{~S}$ and M50 Frame Rotors: Fig.2 shows the meshing of $100 \mathrm{~S}$ and $\mathrm{M} 50$ rotors. 

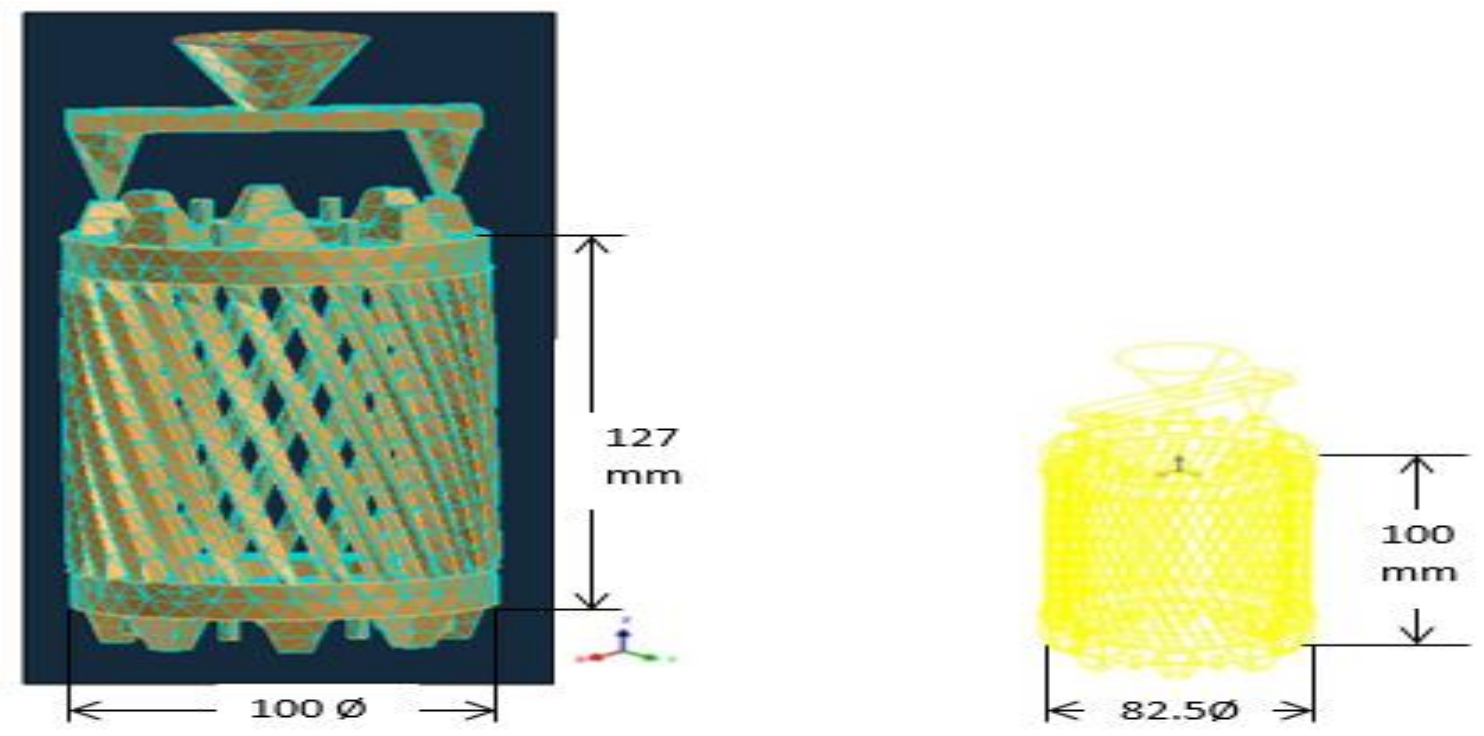

Fig.2: Mesh Model of the 100S and M50 Frame Rotors.

\section{For 100S Rotors:}

$$
\begin{aligned}
& \mathrm{w}=3.2+0.6 * 6.6=7.16 \mathrm{~kg} \\
& \mathrm{C}_{\mathrm{p} \ell}=1146 \mathrm{~J} / \mathrm{KgK} \\
& \mathrm{C}_{\mathrm{ps}}=897 \mathrm{~J} / \mathrm{KgK} \\
& \ell=107.9 \mathrm{~J} / \mathrm{kg} \\
& \mathrm{T}_{\ell}=690^{\circ} \mathrm{C} \text { for pure Alluminium } \\
& \mathrm{T}_{\mathrm{s}}=600^{\circ} \mathrm{C}
\end{aligned}
$$

Therefore,

$\mathrm{Q}_{2}=$ Is the amount of heat injected by Casting

$\mathrm{Q}_{2}=\mathrm{w}\left[\mathrm{C}_{\mathrm{pl}}\left(\mathrm{T}_{1}-\mathrm{T}_{\mathrm{s}}\right)+\mathrm{l}+\mathrm{C}_{\mathrm{ps}}\left(\mathrm{T}_{\mathrm{s}}-423.3\right)\right]$

$$
\mathrm{Q}_{2}=1874114.25 \mathrm{~J}
$$

$\mathrm{Q}_{3}=$ Is the amount of thermal energy transferred from the casting to the mould

$$
\begin{aligned}
\mathrm{Q}_{3} & =\alpha \mathrm{A}\left(\mathrm{T}_{\mathrm{l}}-\mathrm{T}_{\mathrm{m}}\right) \mathrm{t} \\
\alpha & =62 \mathrm{w} / \mathrm{m}^{2} \mathrm{k} \\
\mathrm{A} & =0.00785 \mathrm{~m}^{2} ; \quad \mathrm{D}=100 \mathrm{~mm} \\
\mathrm{t} & =38 \mathrm{sec} \\
\mathrm{Q}_{3}=18.4946 & \left(690-\mathrm{T}_{\mathrm{m}}\right)
\end{aligned}
$$

$\mathrm{Q}_{4}=$ Is the amount of heat minus the heat of the mould

$\mathrm{Q}_{4}=\mathrm{wC}_{\mathrm{ps}}\left(\mathrm{T}_{2}-20\right)$ leaving the casting

$\mathrm{T}_{2}=310^{\circ} \mathrm{C}$

$\mathrm{Q}_{4}=186230.8 \mathrm{~J}$

From balance equation (7),

$\mathrm{w}\left[\mathrm{C}_{\mathrm{pl}}\left(\mathrm{T}_{\mathrm{l}}-\mathrm{T}_{\mathrm{s}}\right)+\mathrm{l}+\mathrm{C}_{\mathrm{ps}}\left(\mathrm{T}_{\mathrm{s}}-423.3\right)\right]=\alpha \mathrm{A}\left(\mathrm{T}_{\mathrm{l}}-\right.$ $\left.\mathrm{T}_{\mathrm{m}}\right) \mathrm{t}+\mathrm{wC}_{\mathrm{ps}}\left(\mathrm{T}_{2}-20\right)$

$$
\mathrm{T}_{\mathrm{m}}=63.68^{\circ} \mathrm{C}
$$

Therefore the preheating temperature of the mould required is $63.68{ }^{\circ} \mathrm{C}$ to balance the heat cycle resulting in six sigma quality rotors.

For M50 Frame Rotor:

$$
\begin{aligned}
& \mathrm{w}=4.8 \mathrm{~kg} \\
& \mathrm{Q}_{2}=1256389.44 \mathrm{~J} \\
& \mathrm{t}=20 \mathrm{sec} \\
& \mathrm{Q}_{3}=12.6542\left(690-\mathrm{T}_{\mathrm{m}}\right) \\
& \mathrm{Q}_{4}=1248624 \mathrm{~J}
\end{aligned}
$$

From balance equation (7),

$$
\begin{gathered}
\mathrm{w}\left[\mathrm{C}_{\mathrm{pl}}\left(\mathrm{T}_{1}-\mathrm{T}_{\mathrm{s}}\right)+\mathrm{l}+\mathrm{C}_{\mathrm{ps}}\left(\mathrm{T}_{\mathrm{s}}-423.3\right)\right]=\alpha \mathrm{A}\left(\mathrm{T}_{1}-\right. \\
\left.\mathrm{T}_{\mathrm{m}}\right) \mathrm{t}+\mathrm{wC}_{\mathrm{ps}}\left(\mathrm{T}_{2}-20\right) \\
\mathrm{T}_{\mathrm{m}}=76.33^{\circ} \mathrm{C}
\end{gathered}
$$

Therefore the preheating temperature of the mould required is $76.33^{\circ} \mathrm{C}$ to balance the heat cycle resulting in six sigma quality rotors.

\section{Simulation AND Results}

\section{A. Monitoring of Mould Temperature}

The evolution of the mould temperature during the preheating cycle's simulation for M50 and 100S frame rotor can be observed in Fig. 3 and Fig. 4, During each simulation

it was observed that temperature was attaining peak point of $475^{\circ} \mathrm{C}$, which directly effects filling time. 


\section{Mold thermal evolution \\ during pre-heating cycles simulation}

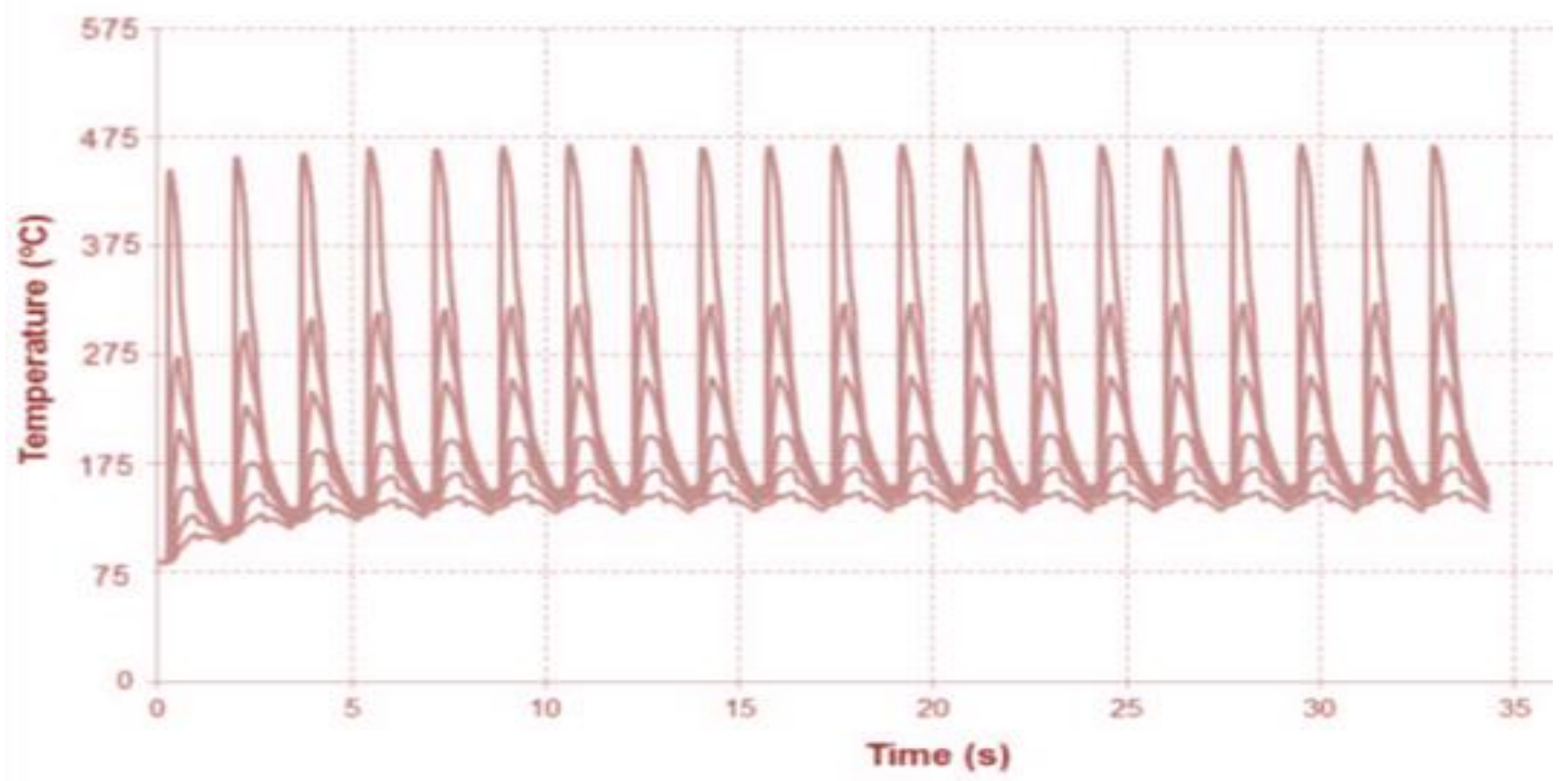

Fig.3: Mould Thermal evolution during pre-heating of M50 Rotor cycles simulation

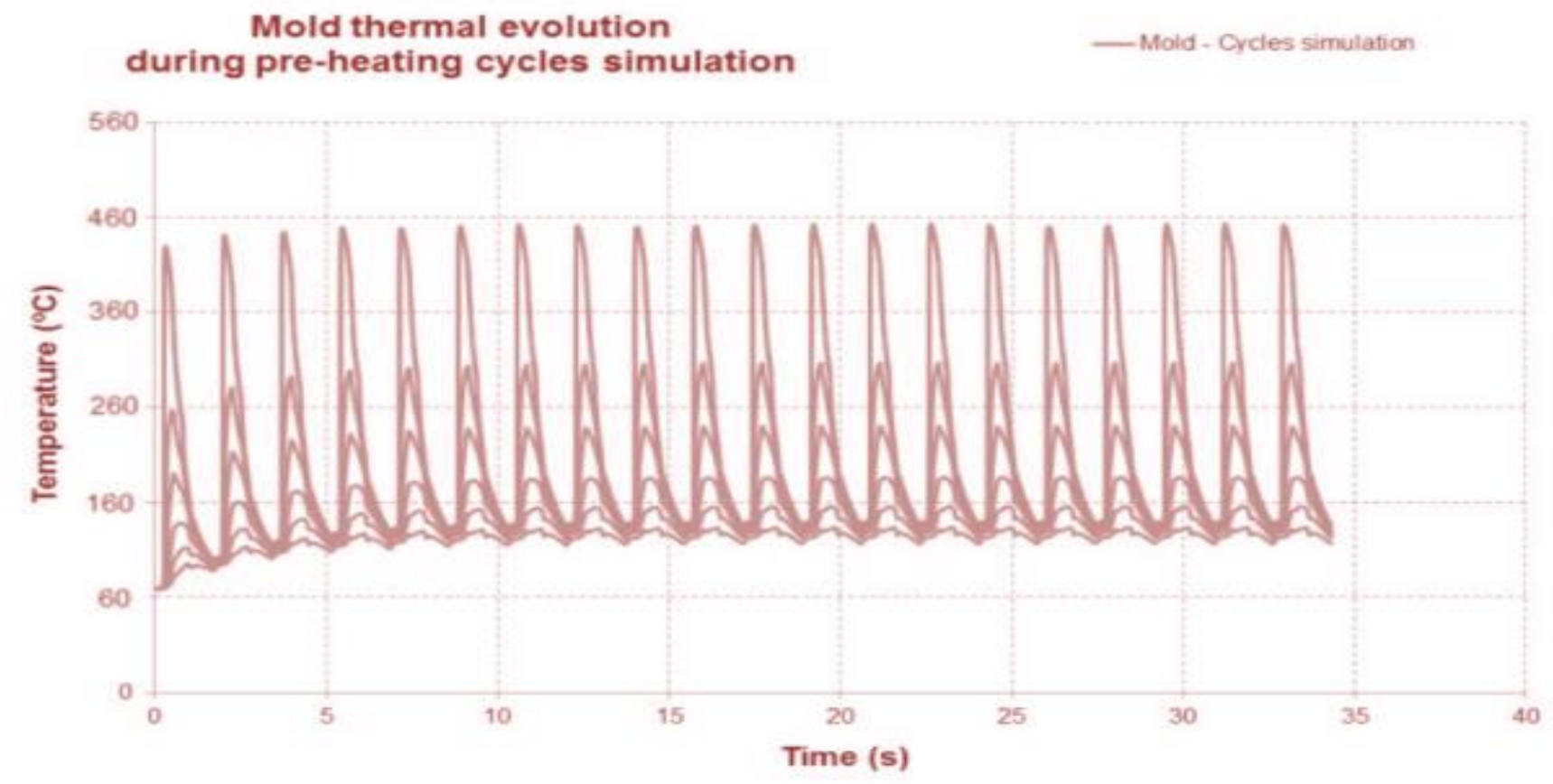

Fig 4: Mould thermal evolution during pre-heating of 100 S Rotor cycle simulation 
The temperature of the mould can control by regulating the flow of the Cooling system through the mould. Fig.5 and Fig. 6 show the mould temperature at a variable flow rate of the cooling system.so every time preheating is not required we can set the required flow to maintain the mould temperature. The temperature of the mould is maintained for minimum filling time and life of the mould.

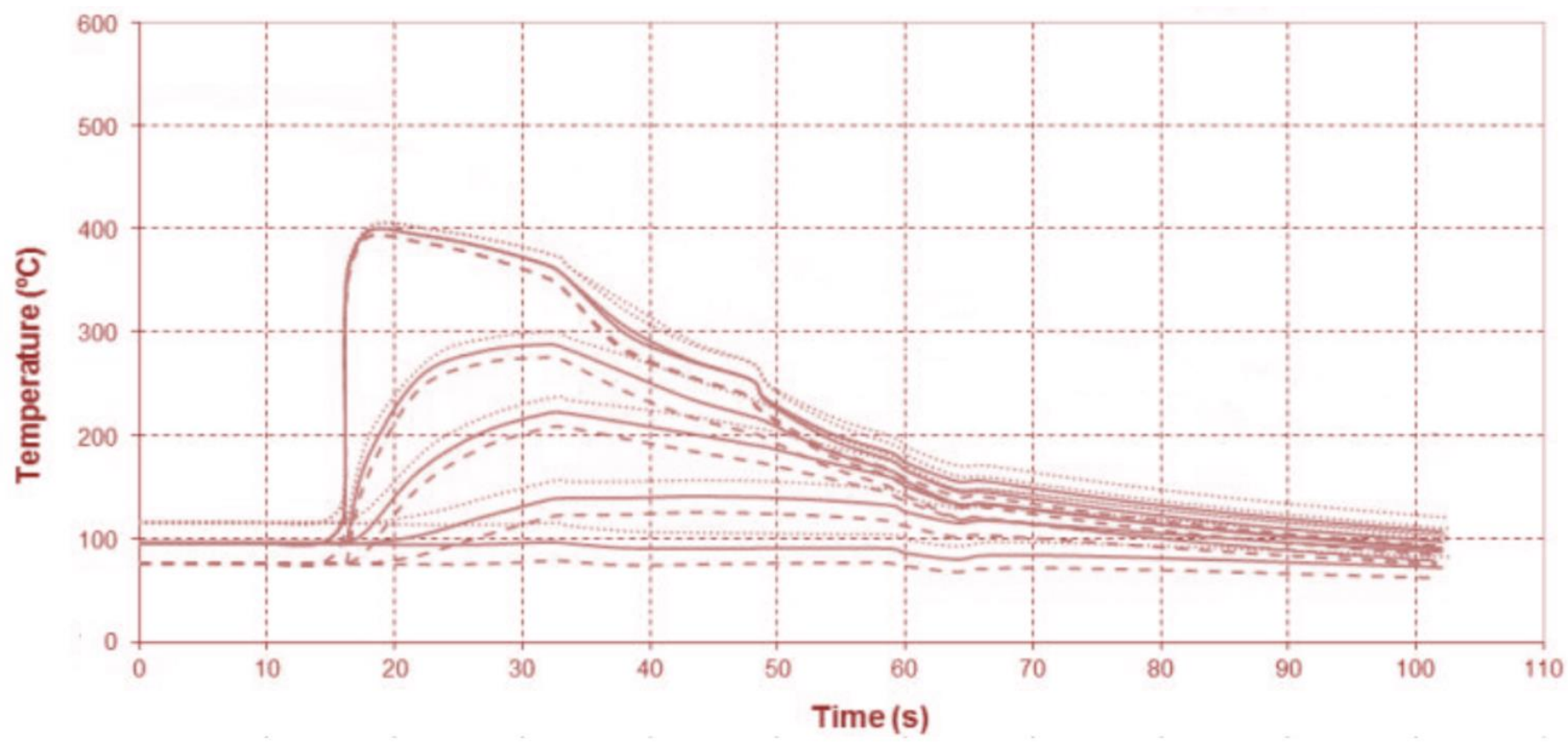

Fig 5: Mould temperature for M50 rotor

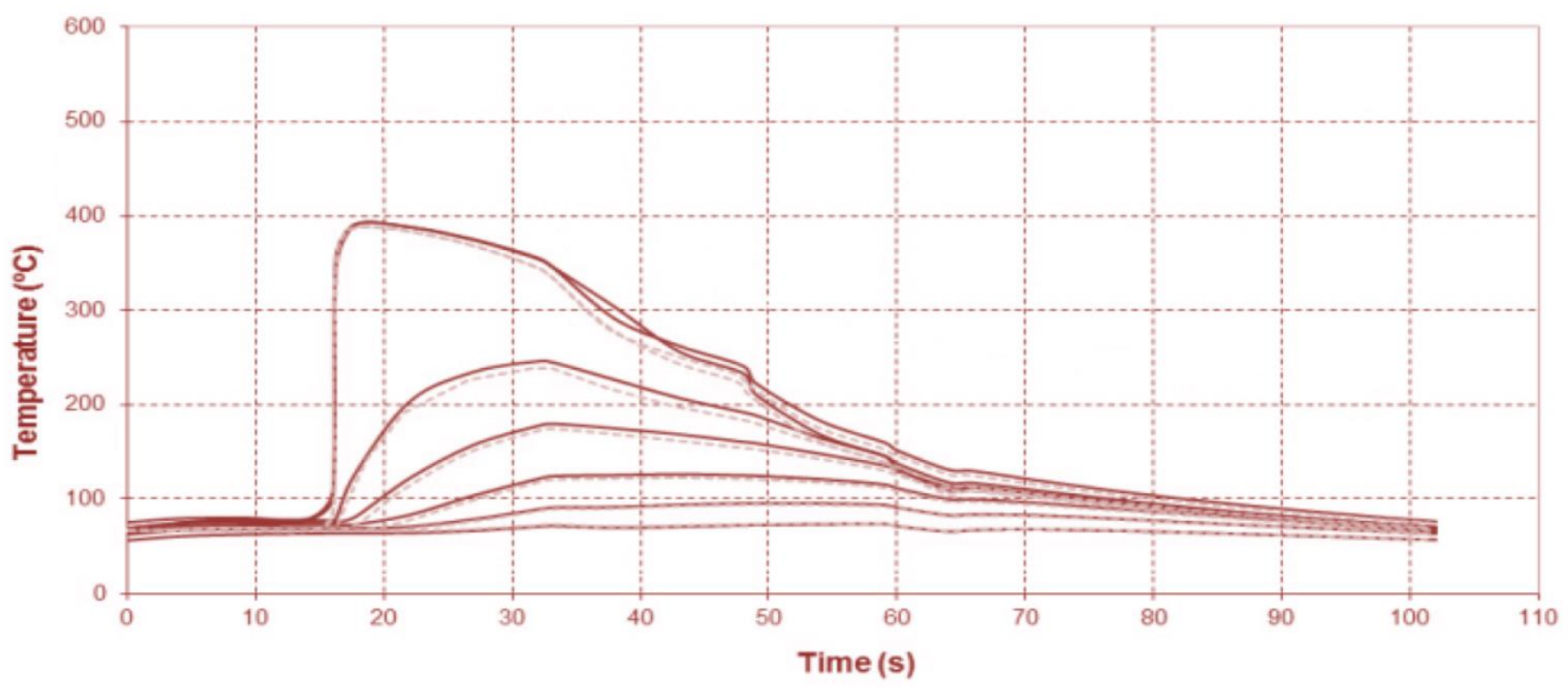

Fig 6: Mould Temperature for 100S Rotor 


\section{B. $\quad$ Simulation of the pre-heating, without preheating temperature cycles and Filling time}

The same results were validated by ProCast simulation software. Table: 1 shows the initial conditions for the simulation cycles. Table: 2 shows the simulation results for filling time for M50 and 100S frame rotors. The main input to the ProCast Simulation is the structured meshed geometry of mould containing part cavity, feeders, gating channels, cores, chills, insulation, etc. Along with the relevant material properties (density, specific heat, thermal conductivity). The geometric elements are created during methods design functions in ProCast, and the property values are taken from a comprehensive database of casting alloys and other materials. Other important parameters include the appropriate boundary and initial conditions, filling time and pouring temperature. All inputs for M50

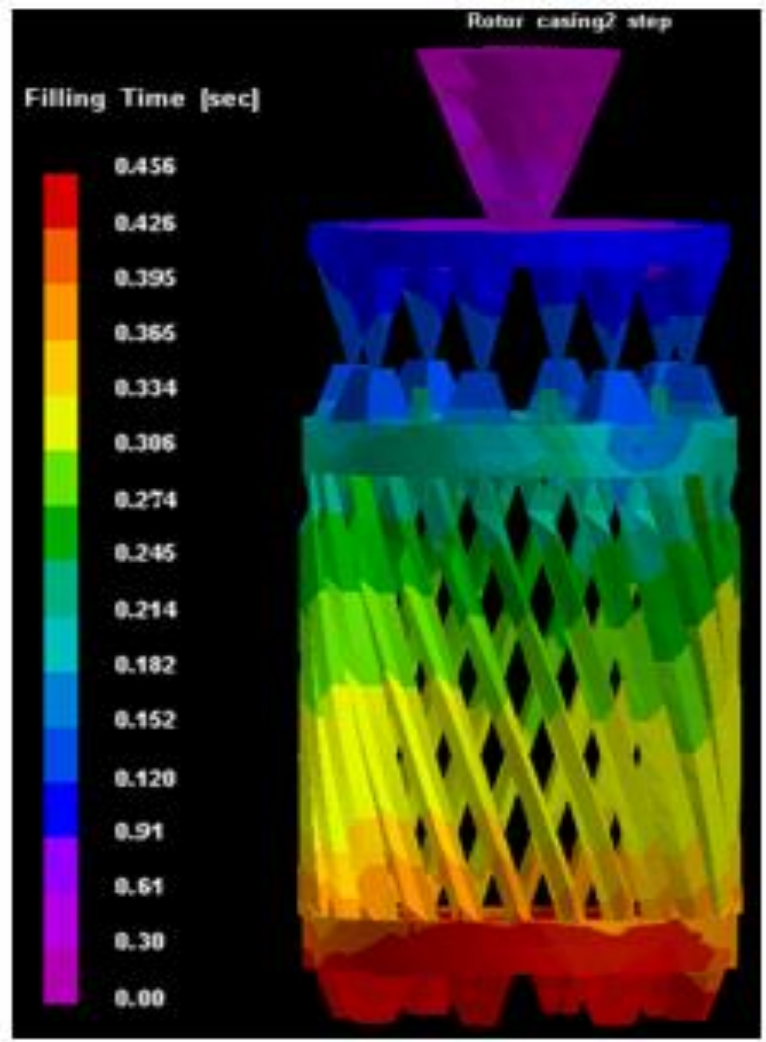

and $100 \mathrm{~S}$ frame rotors are provided, and the filling time before and after preheating was computed.

Fig. 7 and Fig. 8 shows the simulation results for $100 \mathrm{~S}$ and M50 frame rotors for filling time with preheating and without preheating.

TABLE 1: INITIAL CONDITIONS FOR SIMULATION CYCLES

\begin{tabular}{|c|c|}
\hline Software & Pro-Cast \\
\hline Type of Die Casting & HPDC \\
\hline Molten Temperature $^{\circ} \mathrm{C}$ & 680 \\
\hline Specific Heat of Molten Aluminium $(\mathrm{J} / \mathrm{KgK})$ & 1146 \\
\hline Latent Heat of Solid Aluminium $(\mathrm{J} / \mathrm{kg})$ & 107.9 \\
\hline Specific Heat of Solid Aluminium: $(\mathrm{J} / \mathrm{KgK})$ & 897 \\
\hline Heat Transfer Coefficient $\left(\mathrm{Wm}^{-2} \mathrm{k}^{-1}\right)$ & 62 \\
\hline
\end{tabular}

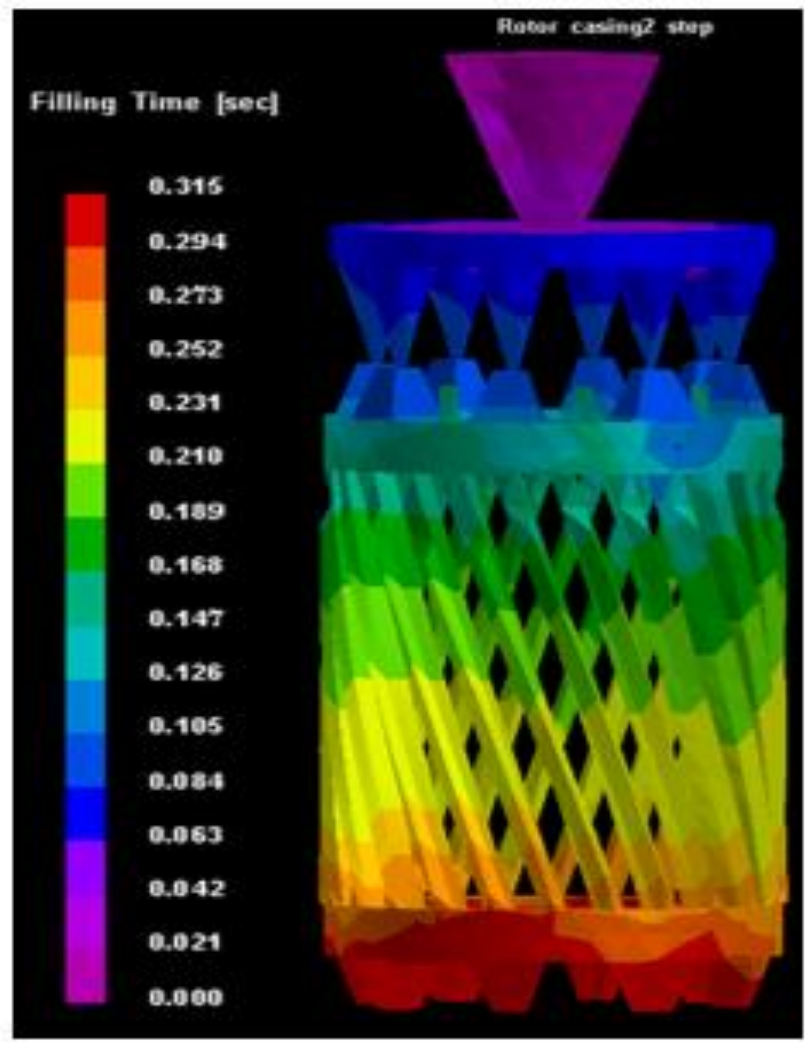

Fig 7: Simulated results for 100 S rotor for filling time 

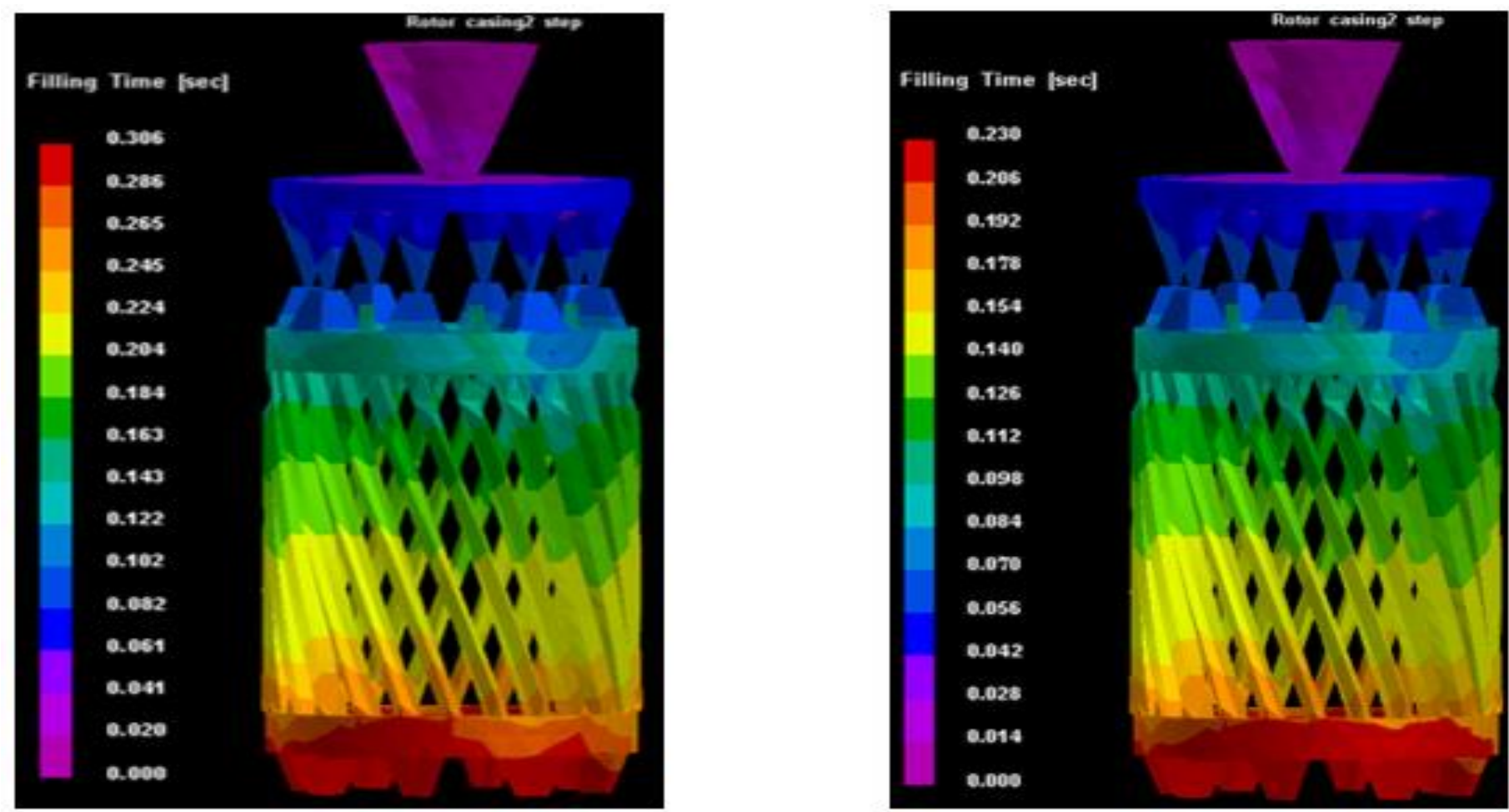

Fig 8: Simulated results for M50 rotor for filling time

TABLE 2: SIMULATION FILLING TIME RESULTS FOR PREHEATING AND WITHOUT PREHEATING

\begin{tabular}{|c|c|c|c|}
\hline \multirow[t]{2}{*}{ Components } & \multirow{2}{*}{$\begin{array}{l}\text { Mould } \\
\text { temperature }\end{array}$} & \multicolumn{2}{|c|}{ Filling time } \\
\hline & & $\begin{array}{l}\text { Preheating } \\
\text { (Sec) }\end{array}$ & $\begin{array}{c}\text { Without preheating } \\
(\mathrm{Sec})\end{array}$ \\
\hline $\begin{array}{l}\text { 100S Rotor } \\
\mathrm{L}=127 \mathrm{~mm} \\
\mathrm{D}=100 \mathrm{~mm}\end{array}$ & 63.68 & 0.315 & 0.436 \\
\hline $\begin{array}{l}\text { M50 Rotor } \\
\mathrm{L}=100 \mathrm{~mm} \\
\mathrm{D}=82.5 \mathrm{~mm}\end{array}$ & 76.66 & 0.230 & 0.306 \\
\hline
\end{tabular}

\section{CONCLUSION}

The present study is an attempt to tackle one of the thermal factors, preheating temperature of the die casting process based on the thermal cycle of the die casting. Work is aimed at the evaluation of the impact of thermal factors preheating temperature on the quality of the HPDC product. The result of the balance thermal equation shows good agreement with the available data for different sizes of the casting on the HPDC machine.

1) According to the simulated analysis with preheating, without preheating temperature and filling time, it is observed that the filling time is less in case of preheating temperature. The Thermal balance equation is beneficial to improve the thermal parameters, predicting the defects related to the filling process, as to achieve the six sigma products.

2) It is observed that the preheating temperature evaluated from the thermal equation should be maintained throughout the die casting cycle by maintaining the flow of the cooling system into the container.
3) Using a heat balance equation and finding the preheating temperature waste shot can be eliminated.

\section{REFERENCES:}

[1] A.K.Sahoo, M.K. Tiwari, A.R.Mileham "Six Sigma based approach to optimize the radial forging operation Variables" journal of materials processing technology 202, pp.125-136, 2008

[2] Jay M. Patel, Yagnang R. Pandya, Devang Sharma, Ravi C. Patel," Various Type of Defects on Pressure Die Casting for Aluminium Alloys" International Journal for Scientific Research \& Development| Vol. 5, Issue 01, pp 2321-0613, 2017

[3] Santosh S. Dabhole, Chaitanya A. Kurundwad, Sujit R. Prajapati "Design, and development of die casting Die for rejection reduction" International Journal of Mechanical Engineering and Technology, Volume 8, Issue 5, May 2017, pp. 1061-1070

[4] Case Studies of Innovative Die-casting Machines, Alessandro Benini - Italpresse, Brescia, Italy

[5] Darina Matiskova, Stefan Gaspar and Ladislac Mura "Thermal Factors of Die Casting and Their Impact on The Service Life of Moulds and the Quality of Castings" Journal of Acta Polytechnica Hungarica, Vol.10, No. 3, 2013

[6] Sk.Nagoor Vali, S.Sureshkumar, M.A.Athiya, K.Manigandan, and H.Fayazdeen "A review on die-casting Process parameters", International Journal of Scientific Research and Review, Vol. 7, Issue 3, 2018

[7] Stefan Gaspar, "Technological Factors of Pressure Die Casting" Annals of faculty Engineering Hunedora, International Journal of Engineering Tome IX (the year 2011).

[8] Xiong Shoumei, F. Lau, W.B. Lee "An efficient thermal analysis system for the die-casting process"Journal of Materials Processing Technology 128 (2002) 19-24

[9] P.K. Seo, D.U. Kim and C.G. Kang "Effects of die shape and injection conditions proposed with Numerical integration design on liquid segregation and mechanical properties in semi-solid die casting Process" Journal of Materials Processing Technology, Vol.176, pp.45-54, 2006. 
[10] C. Mohanty1, B. K. Jena, "Optimization of Aluminium Die Casting Process Using Artificial Neural Network International Journal of Emerging Technology and Advanced Engineering (ISSN 2250-2459, Volume 4, Issue 7, July 2014)

[11] Satish Kumar, Arun Kumar Gupta, Pankaj Chandna," Optimization of Process Parameters of Pressure Die Casting using Taguchi Methodology" World Academy of Science, Engineering and Technology Vol: 6, 2012.

[12] Henry Hu, Fang Chen, Xiang Chen, Yeou-li Chu, Patrick Cheng, "Effect of cooling water flow rates on Local temperatures and heat transfer of casting dies, Journal of Materials Processing Technology 148(2004) 57-67

[13] L.X. Kong, F.H. She, W.M. Gao, S. Nahavandi, P.D. Hodgson, "Integrated optimization system for high Pressure die casting processes" Journal of materials processing technology 201 (2 $000)$ 629-634

[14] Senthiil P, V. M.Chinnapandian and Sirushti, "Optimization of Process Parameters in Cold Chamber Die Casting Process Using Taguchi Method "IJISET - International Journal of Innovative Science, Engineering \& Technology, Vol. 1 Issue 6, August 2014.

[15] V. E. Bazhenov, A.V. Koltygin, and A. V. Fadeev "The Use of the ProCast Software to Simulate the Process of Investment Casting of Alloy Based on Titanium Aluminide TNM_B1 into Ceramic Molds" Russian Journal of Nonferrous Metals, Vol. 55, No. 1, pp. 15-19, 2014.

[16] Hong Yan, Wenwei Zhuang, Yong Hu, Qiansheng Zhang, Hong Jin," Numerical simulation of AZ91D Alloy automobile plug-in pressure die casting process" Journal of Materials Processing Technology 187-188 (2007) 349-353

[17] S.M. Xiong, F. Lau, W.B. Lee, L.R. Jia, "Numerical methods to improve the computational efficiency ofThermal analysis for the die casting process" Journal of Materials Processing Technology 139 (2003) 457-461

[18] Matthew S. Dargusch, G. Dour, N. Schauer, C.M. Dinnis, G. Savage, "The influence of pressure during Solidification of high-pressure die-cast aluminium telecommunications components" Journal of MaterialsProcessing Technology.2006

[19] B.Kosec, G.Kosec, M. Sokovia," Temperature Field and Failure analysis of die casting die, 'International Scientific Journal, Vol.28, Issue3, 2007 